\title{
Operational retrieval of Asian sand and dust storm from FY-2C geostationary meteorological satellite and its application to real time forecast in Asia
}

\author{
X. Q. Hu ${ }^{1,3}$, N. M. Lu ${ }^{1}$, T. Niu ${ }^{2}$, and P. Zhang ${ }^{1}$ \\ ${ }^{1}$ Key Laboratory of Radiometric Calibration and Validation for Environmental Satellites (KLRCV), National Satellite \\ Meteorological Center, China Meteorological Administration (NSMC/CMA), Beijing 100081, China \\ ${ }^{2}$ Centre for Atmosphere Watch \& Services (CAWAS), Chinese Academy of Meteorological Sciences, China Meteorological \\ Administration (CMA), Beijing 100081, China \\ ${ }^{3}$ Institute of remote sensing applications, Chinese Academy of Sciences, Beijing 100101, China
}

Received: 28 March 2007 - Published in Atmos. Chem. Phys. Discuss.: 18 June 2007

Revised: 8 January 2008 - Accepted: 25 January 2008 - Published: 18 March 2008

\begin{abstract}
This paper describes an operational retrieval algorithm for the sand/dust storm (SDS) from FY-2C/SVISSR (Stretched-Visible and Infrared Spin-Scan Radiometer) developed at the National Satellite Meteorological Center (NSMC) of China. This algorithm, called Dust Retrieval Algorithm based on Geostationary Imager (DRAGI), is based on the optical and radiative physical properties of SDS in mid-infrared and thermal infrared spectral regions as well as the observation of all bands in the geostationary imager, which include the Brightness Temperature Difference (BTD) in split window channels, Infrared Difference Dust Index (IDDI) and the ratio of middle infrared reflectance to visible reflectance. It also combines the visible and water vapor bands observation of the geostationary imager to identify the dust clouds from the surface targets and meteorological clouds. The output product is validated by and related to other dust aerosol observations such as the synoptic weather reports, surface visibility, aerosol optical depth (AOD) and ground-based $\mathrm{PM}_{10}$ observations. Using the SDS-IDD product and a data assimilation scheme, the dust forecast model CUACE/Dust achieved a substantial improvement to the SDS predictions in spring 2006.
\end{abstract}

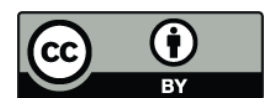

Correspondence to: X. Q. Hu (hxq@nsmc.cma.gov.cn)

\section{Introduction}

SDS is recognized to have a very wide range of environmental impacts. When it occurs, SDS can move forward like an overwhelming tide with drifting sands to bury farmlands, denude steppe, attack human settlements, reduce the temperature, pollute the atmosphere, hurt animals and destroy mining and communication facilities. On the other hand, atmospheric mineral-dust loading is one of the largest uncertainties in global climate-change modeling and is known to have an important impact on the radiation budget and atmospheric instability. Brooks (2000) provided tentative evidence of a possible positive feedback mechanism involving rainfall and dust variability. Dust also has an impact on the nutrient dynamics and biogeochemical cycling of ecosystems, and it has a major influence on soil characteristics, oceanic productivity, and air chemistry. Moreover, because of the thousands of kilometers over which dust is transported, it has an influence at great distances from its sources (Gong et al., 2006; Middleton and Goudie, 2001).

Since the surface observations are generally sparse in the desert region, it is difficult to locate the dust emission source as well as the movement of dust outbreak. The disadvantage of surface observation with coarse horizontal resolution can be overcome with the aid of satellite remote sensing. Earlier researchers utilized satellite visible and infrared measurements to detect dust storm over land and water (Shenek and Curran, 1974) and others utilized visible spectrum to monitor dust outbreaks as well as to estimate dust optical depth over oceanic regions (Carlson, 1978; Norton et al.,

Published by Copernicus Publications on behalf of the European Geosciences Union. 


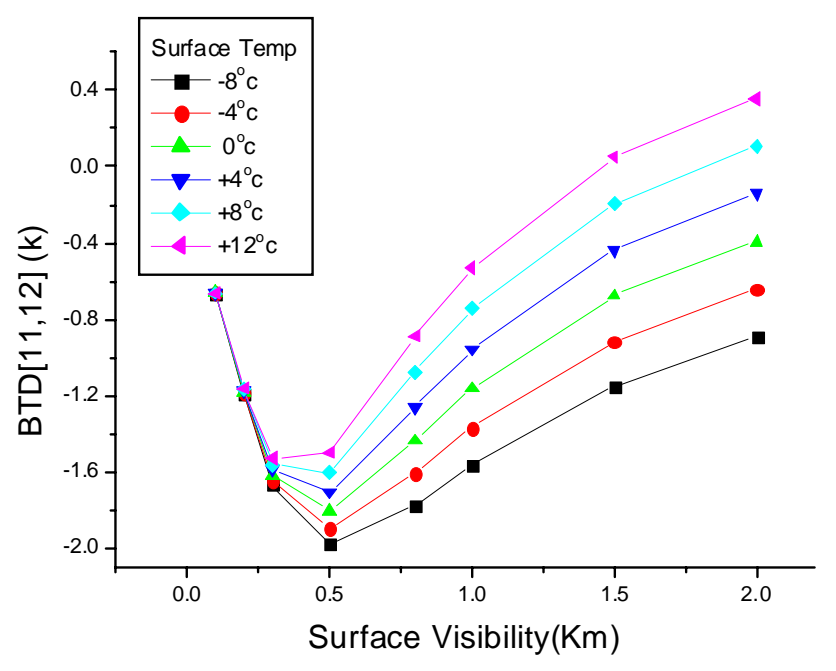

Fig. 1. The relationship between surface visibility and temperature differences as a function of ground surface temperatures for middle latitude winter atmosphere.

1980). However, monitoring dust aerosol outbreaks over land using satellite visible and near-infrared data is difficult due to the bright underlying desert surface. More recent studies have shown the significant potential of using thermal infrared data to detect Saharan dust over land (Cautenet et al., 1992; Legrand et al., 1992, 1988, 1989, 2001). It was shown that dust haze, through the impact of radiation process, cuts down the heating effect on land surface during the daytime and slows down the cooling effect near ground surface during the nighttime. A correlation between the brightness temperature difference (11-3.7 $\mu \mathrm{m})$ and dust outbreaks was proposed by Ackerman (1989) and later a tri-spectral $(8,11$ and $12 \mu \mathrm{m})$ technique for detecting dust over water and for distinguishing dust plumes from water/ice clouds was developed (Ackerman, 1997). Some algorithms for the detection of airborne volcanic ash introduced in the last years have been introduced such as three infrared bands (3.9, 10.7, and $12.0 \mu \mathrm{m}$ ) method (Ellrod et al., 2003; Pergola et al., 2004) and four spectral channels $(0.65,3.75,11$, and $12 \mu \mathrm{m}$ ) method (Pavolonis et al., 2006). These techniques can be used for the reference of dust storm detection because there are some similar characteristics in spectral-absorption and scattering between them in atmosphere.

This paper describes an operational retrieval algorithm of Asian SDS from FY-2C satellite developed by integrating all optical and radiance mechanism of dust storm in middle infrared and thermal infrared bands. The dust storm detection product is one of the most important operational products from Data Processing Center (DPC) of FY-2C ground application system. This product is used for the assimilation of dust forecast model UACE/Dust as one important data source of the initiative dust distribution field. Using the SDS-IDD product and a data assimilation scheme, the CUACE/Dust achieved a substantial improvement to the SDS predictions in spring 2006 (Niu et al., 2007).

\section{Dust retrieval algorithm based on geostationary im- ager}

\section{$2.1 \quad$ FY-2C Satellite}

FY-2C is China's first operational geostationary meteorological satellite operated by National Satellite Meteorological Center (NSMC) of China Meteorological Administration (CMA). It was successfully launched on 19 October 2004, as the improved successor of previous experimental GEO satellites FY-2A and FY-2B which were launched on 10 June 1997 and 25 June 2000, respectively. The satellite was placed in the geostationary orbit over $105^{\circ} \mathrm{E}$ with a field of view that covers the areas of Asian and Pacific Region. FY-2C is spinstabilized with a rotation velocity $100 \mathrm{rpm}$. The main payload onboard, the upgraded Stretched-Visible and Infrared Spin-Scan Radiometer (S-VISSR), features 5 spectral bands (1 VIS and 4 IR) (detail in Table 1). These new specifications of the sensor improve the following instrumental observation functions: (1) the capability of detecting and calculating water vapor contents, to support semi-transparent ice cloud detecting, and to have a better accuracy of atmospheric absorption correction for better sea temperature estimation; (2) improved temperature resolution of the IR bands and SNR of the VIS band; support of split window application; (3) the data quantization level of the IR bands has been increased from 256 ( 8 bit) to 1024 (10 bit).

\subsection{Algorithm physical basis}

\subsubsection{IR split widow technique}

The most commonly used satellite-based volcanic ash detection technique is often referred to as the "reverse absorption" technique (Prata, 1989a, b), which uses brightness temperatures in the 11 and $12 \mu \mathrm{m}$ regions of the spectrum. SDS has the similar absorption characteristic as the volcanic silicate in the thermal region (Ackerman, 1997). Quartz displays a strong spectral dependence in the imaginary index of refraction, suggesting that spectral difference techniques may be successful in detecting SDS with a large sand component. At the same time, the thermal infrared spectra of minerals strongly depend on the particle size and there is a temperature difference between the surface and the SDS in air (Wald et al., 1998). When the dust layer is optically thick, the dust particles cause a negative brightness temperature difference (i.e. $\operatorname{BTD}[11,12]<0$, where $\operatorname{BTD}[11,12]$ defines the 11 $12-\mu \mathrm{m}$ brightness temperature difference). Using BTD $[11$, 12] to discriminate dust cloud from meteorological clouds is called the "IR split windows" technique.

Figure 1 shows the simulated BTD[11, 12] signals of different dust loading using MODTRAN radiative transfer 
Table 1. Specification of S-VISSR/FY-2C.

\begin{tabular}{llll}
\hline Specification/spacecraft & & FY-2A/2B & FY-2C \\
\hline \multirow{3}{*}{ Bands $(\mu \mathrm{m})$} & Visible & $0.50-1.05$ & $0.55-0.90$ \\
& IR thermal & $10.5-12.5$ & IR11: 10.30-11.30 \\
& Mid-IR & NO $12.11 .50-12.50$ & $3.50-4.00$ \\
& IR Water vapor & $6.30-7.60$ & $6.30-7.60$ \\
IFGOV ( $\mu \mathrm{rad})$ & Visible & 40 & 35 \\
\multirow{2}{*}{ Spatial resolution $(\mathrm{km})$} & IR (all 4 bands) & 160 & 140 \\
& visible & 1.44 & 1.25 \\
& IR (all 4 bands) & 5.76 & 5 \\
Range of Dynamic & Visible(reflectance) & $0-98 \%$ & $0-98 \%$ \\
& IR (TB) & $180-320 \mathrm{~K}$ & $180 \mathrm{~K}-330 \mathrm{~K}$ \\
& Mid-IR(TB) & NO & $180 \mathrm{~K}-340 \mathrm{~K}$ \\
& Water vapor (TB) & $200-300 \mathrm{~K}$ & $190 \mathrm{~K}-300 \mathrm{~K}$ \\
Data Quantization & Visible & 6 bits & 6 bits \\
& IR (all 4 bands) & 8 bits & 10 bits \\
\hline
\end{tabular}

model (Berk et al., 1989) at the middle-latitude winter. It is found that no matter what the surface temperatures are, the absolute value of negative BTD $[11,12]$ always increases with the lower surface visibility (meaning more dust) when the visibility is higher than $500 \mathrm{~m}$, but the relation trend of the absolute BTD $[11,12]$ reverses at the point when the surface visibility becomes very poor (heavy dust storm, visibility is less than $500 \mathrm{~m}$ ). This kind of feature for SDS is found from the actual image observed by the satellite. In addition, BTD $[11,12]$ in the thermal split window channels depends on the density of airborne dust. The magnitude of negative BTD $[11,12]$ is driven by (1) the thickness of the dust layer (temperature), (2) the mass per area of dust cloud (concentration), (3) the composition of airborne dust (refractive index) and (4) the size of the dust particles (size distribution). The dust BTD $[11,12]$ in different height (Tbb), different mean effective radius (Ref) and different loading (AOD) over the same surface was also simulated by DISORT (Zhang et al., 2006). This simulation can explain most of the signal from satellite observation of the dust aerosols.

Unfortunately, such a method does not often seem to have a "stable" behaviour, showing a strong dependence on the observational conditions and/or on the nature (such as underlying surface type, surface winds and mixture of clouds) and characteristics of dust clouds. Moreover, a high concentration of atmospheric water vapour can compensate for the reverse absorption effect of dust (Simpson et al., 2000). There is also the annual cycle of surface heating due to variations in the solar illumination, but this effect can be easily accounted for.

\subsubsection{Infrared Difference Dust Index (IDDI)}

To detect the presence of desert dust over Africa in view of climatological applications, the Infrared Difference Dust Index (IDDI) was developed as a satellite dust product designed from midday Meteosat-IR imagery, specifically for dust remote sensing in arid regions such as the Sahel and Sahara (Legrand et al., 2001). To take advantage of the impact of dust aerosols on the thermal infrared radiance outgoing to space, IDDI is based on observing thermal radiation (10$12 \mu \mathrm{m}$ ) emitted by the same scene over the course of several days, during which time the mineral aerosol content of the atmosphere has changed. The principal assumptions behind this method are (i) the radiance emitted by the surface is constant or linearly varying over the time period of the observations, and (ii) one of the days is dust free. In the presence of dust, the outgoing longwave radiation is attenuated along its path through the dust layer, resulting in a reduction in the outgoing longwave radiation when compared to a clear day. Furthermore, the solar flux available to heat the surface is reduced by the presence of dust aerosols due to enhanced scattering of shortwave radiation, which in turn leads to a drop in the surface temperature. Both of these effects reduce the thermal infrared radiation emitted to space, thereby increasing the contrast between observations obtained during clear and dusty conditions. This thermal contrast can in turn be related to dust loading. The Infrared Difference Dust Index (IDDI) is defined as:

IDDI $=T_{\text {ref }}-T_{b b}$

where $T_{b b}$ is the observed brightness temperature by sensor from space, $T_{\mathrm{ref}}=T_{b b}(\max )$ is maximum value over the 10day period of the reference image. 


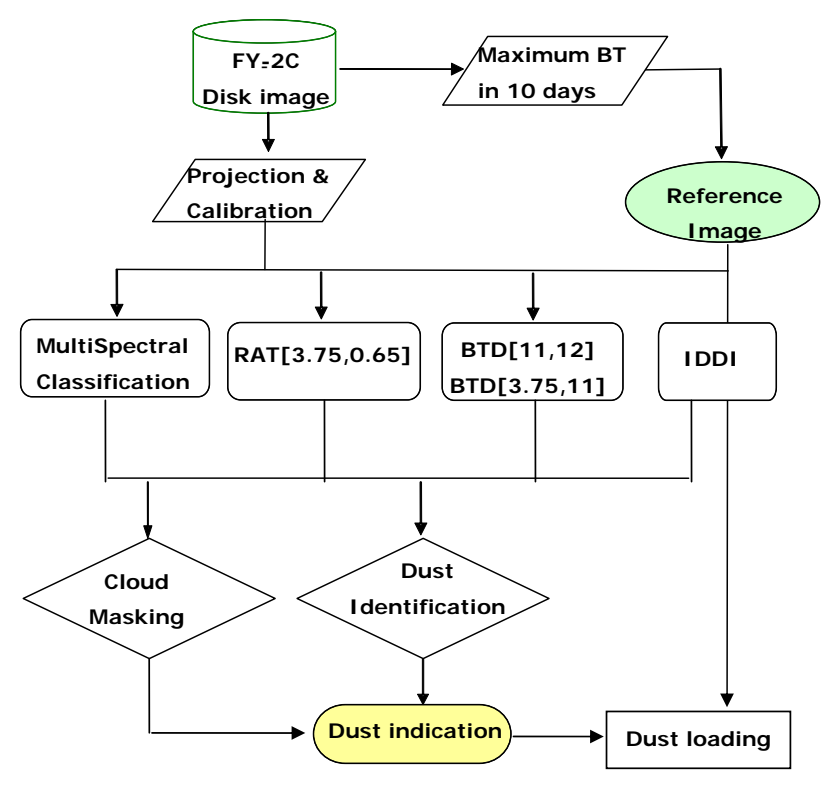

Fig. 2. DRAGI data processing flow chart.

\subsubsection{Middle infrared method}

Ackerman (1989) proposed a technique to track the dust cloud based on the difference between band 3 and 4 of AVHRR. The measurements of refractive index of dust show that large differences exist at wavelengths of 3.7 and $11 \mu \mathrm{m}$. The imaginary part of the index of refraction at $11 \mu \mathrm{m}$ is approximately an order of magnitude greater than that at $3.7 \mu \mathrm{m}$. Therefore, large differences may exist in the equivalent black-body temperatures (BT) at these two bands (i.e. BTD $[3.7,11])$ in the presence of a dust layer, thus providing a method to locate and track dust outbreaks. During the night, dust tends to produce a negative BTD $[3.7,11]$ and different thresholds are required.

In addition to this, the single scatter albedo (SSA) of the airborne particles is a strong function of particle size at wavelengths less than about $2 \mu \mathrm{m}$, with a higher SSA for smaller particles (Pavolonis et al., 2006). At visible wavelengths $(\sim 0.65 \mu \mathrm{m})$, with the exception of very small dust particles (e.g. reff $=0.33 \mu \mathrm{m}$ ), the SSA of dust is significantly smaller than for water and ice clouds, which always have SSA values very close to unity. In the middle-infrared at $3.7 \mu \mathrm{m}$, both dust and water clouds will scatter photons more often than ice clouds. Dust and water clouds can often have similar single scatter albedos in the middle-infrared. As at visible wavelengths, smaller particles tend to have larger SSA values than larger particles, regardless of the composition. Using above information as a reference, Pavolonis et al. (2006) developed a new automated ash detection technique by the ratio of particle reflectance at $3.7 \mu \mathrm{m}$ (R [3.7]) to that at $0.65 \mu \mathrm{m}$ (R[0.65]) (hereafter RAT [3.7, 0.65]). This technique is also used to SDS detection. For a given optical depth, RAT [3.7,
0.65] for dust clouds will often be larger than that for water and ice clouds. However, for a given cloud optical depth, the RAT [3.7, 0.65] for water clouds with small droplets (e.g. reff $<4.0 \mu \mathrm{m}$ ) and dust plumes may be very similar. This suggests that the edges of stratus and fair-weather cumulus clouds may have similar RAT [3.7, 0.65$]$ values as some dust plumes.

\subsection{Algorithm implementation}

An operational retrieval algorithm of dust detection is developed using the data of all bands of FY-2C and called Dust Retrieval Algorithm based on Geostationary Imager (DRAGI) since 2001. The production procedure of dust detection from DRAGI is illustrated in Fig. 2. There are several processing steps before retrieving the SDS location and loading and after generating the reference Image (RI)and IR11 brightness temperature Difference Image (DI): (1) BTD [11, 12] and BTD $[3.7,11]$ calculations based on original image (OI) of IR bands, (2) RAT [3.7, 0.65] calculations based on the satellite observation signal of three bands $3.7 \mu \mathrm{m}, 0.65 \mu \mathrm{m}$ and $11 \mu \mathrm{m}$ as Sect. 2.3.2, and (3) cloud mask generations based on above middle-parameters or factors. The final output products including dust area, location and dust loading IDDI are generated.

\subsubsection{Generating RI and DI}

Figure 3 exhibits the OI, RI and DI covering Northeast Asia on 13 March 2006, at 06:00 UTC. The period used for constructing the RI is ten days (4-13 March). A color scale with the corresponding brightness temperature is available for OI and RI.

The clouds are rather well distinguished due to their brightness and structure. Conversely, dust plumes are not easily discernable because their radiative effect is confused with the pattern of the ground surface radiative effect. The RI image is a clear and clean image showing only the unvarying surface contribution. The coldest surfaces lie in the north and the hottest ones tend to lie in the desert and Gobi in North China. The Mountains and Tibet plateau appear colder than surrounding regions. The other regions are usually covered by all kinds of sparse or dense vegetation and full of large amount of atmospheric water vapor. DI image shows only the variable atmospheric radiative effects. Clouds seen in the OI are restituted (South China, east of Tibet and Russia). A strong dust plume, easy to discriminate from the clouds due to its smoothness and coherence, appears in the Taklamakan in Xinjiang Province.

\subsubsection{BTD and RAT calculations}

BTDs are calculated easily using the subtract operation of brightness temperatures of corresponding bands, but the RAT calculation is a little more complicated. During the daytime, 
FY-2C false color RGB image (R:IR11;

IR11 OI Image

$\mathrm{G}$ : visible; $\mathrm{B}$ : water vapor )
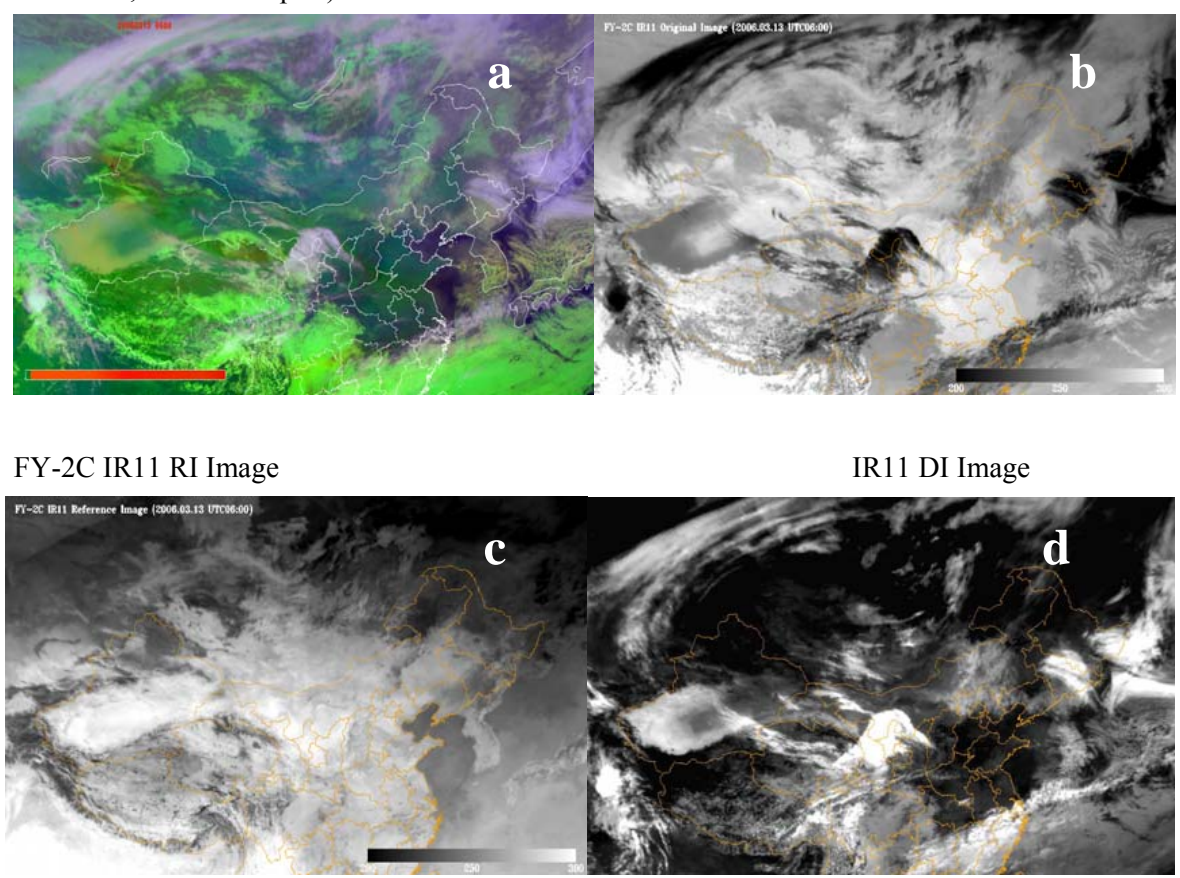

FY-2C BTD $[11,12]$ Image

FY-2C BTD $[3.7,11]$ Image

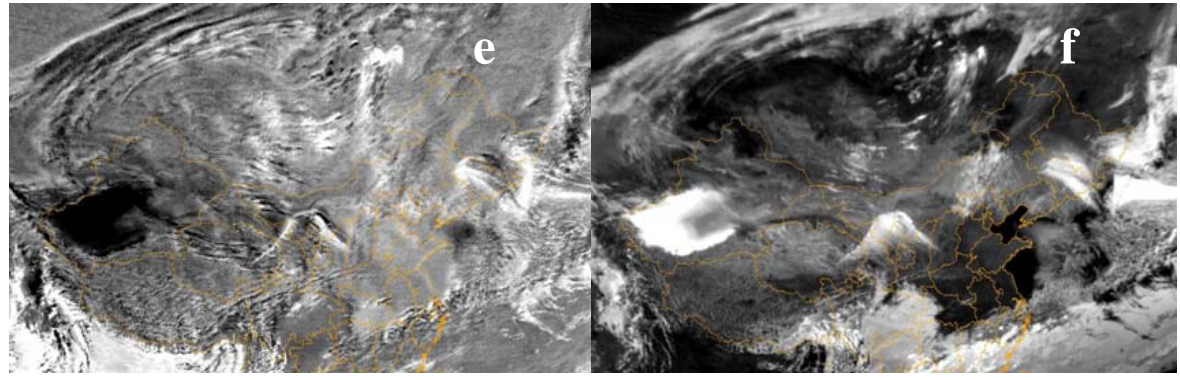

FY-2C IR1 RAT[3.7,0.65] Image

IR11 IDDI Image

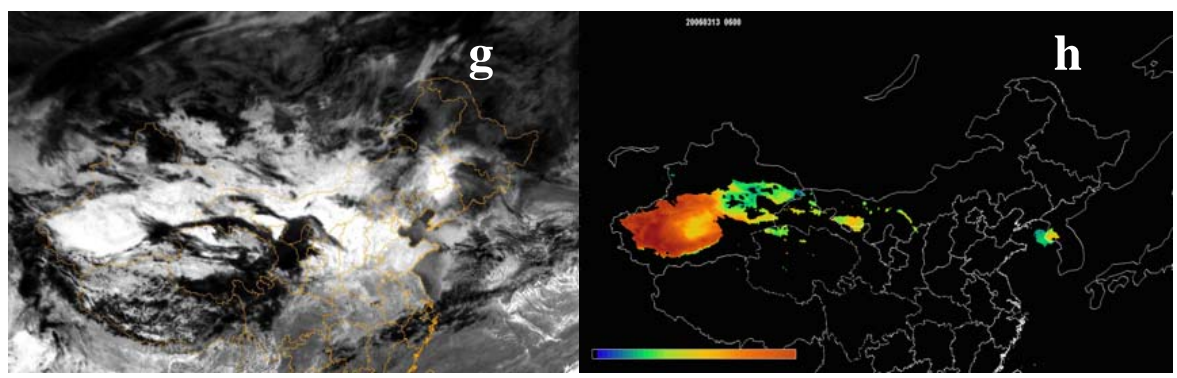

Fig. 3. Illustration of some bands images, calculated images and dust identification IDDI image on 13 March 2006, at 06:00 UTC.

the radiance at middle infrared band $3.7 \mu \mathrm{m}$ has both significant solar and thermal components. To obtain an estimate of the $3.7 \mu \mathrm{m}$ reflectance due to the solar component, the contribution to the total radiance from thermal emission must be approximated and removed. As suggested by Pavolonis et al. (2006), the $3.7 \mu \mathrm{m}$ reflectance estimate $(\mathrm{R}[3.7])$ is calculated as:

$$
R[3.7]=\left(L(3.7)-B\left(T_{11}\right)\right) /\left(L o^{*} u-B\left(T_{11}\right)\right)
$$

where $L(3.7)$ is the observed $3.7 \mu \mathrm{m}$ radiance, $B\left(T_{11}\right)$ is the Planck function radiance at $3.7 \mu \mathrm{m}$ that is calculated using the observed $11 \mu \mathrm{m}$ brightness temperature, Lo is the solar constant for the $3.7 \mu \mathrm{m}$ band (adjusted for earth-sun distance), and $\mathrm{u}$ is the cosine of the solar zenith angle. After that, the ratio RAT [3.7, 0.65] can be calculated. 


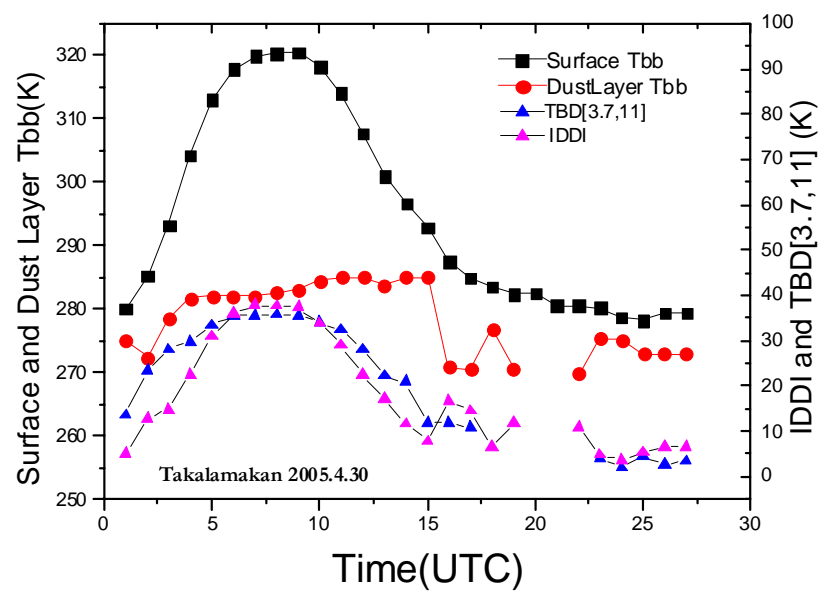

Fig. 4. Surface brightness temperature and IDDI diurnal circle by FY-2C.

\subsubsection{Cloud masking}

Several techniques were adapted to identify the cloud pixel in the OI, including the high reflectance method in VIS channel, the spatial coherence method, IR BTD threshold method, correlation method of water vapor channel and IR channel. During the dust identification, the quality of cloud masks directly affects the result of dust detection. The dust cloud needs to be discriminated from the meteorological cloud to avoid the confusion between cloud and dust targets, which causes missing or false detections of dust targets. In the present, cloud mask is one of the primary operational products of Data Processing Center (DPC) of FY-2C ground application system, but DRAGI does not use this ready-made product because of its confusion between dust and meteorological cloud but generates the cloud mask independently based on a set of the thresholds of meteorological cloud before dust identification. The discrimination factors of cloud are same as the dust target, but the threshold values are different. The threshold values are constructed by using a lot of cloud targets and specially focus on the difference between dust and cloud.

\subsubsection{Dust identification and retrieval}

All dust identification factors are based on the above physical theories and then combined to discriminate the dust storm pixel from the observation. Figure 3 shows a dust case in Taklamakan in Xinjiang Province by FY-2C on 13 March 2006. The apparent attenuation of outgoing surface brightness temperature can been seen from the OI, RI and DI images. At the same time, the negative BTD $[11,12]$ is very clear of dust area. High positive BTD $[3.7,11]$ and high RAT $[3.7,0.65]$ also show the strong scattering of airborne dust. In addition to this, other bands data including water vapor image are used to identify the dust targets. They are com- bined into a dynamic threshold-based classification method. The values of these thresholds are changed according to the observation time and geometry, underlying type and surface temperature (season). A set of thresholds based has been established for the FY-2C observation of dust cases.

The first step of dust thresholds construction is to find the training sample for dust area by manual-identification. The threshold of each channel for the dust target is determined by histogram analysis of the target and the identification is conducted automatically using these thresholds. The classification thresholds are modified by validations with actual dust case. We run several dust cases to construct the threshold values and modified them again and again, finally suitable for all the dust cases. A dynamic threshold corresponding to the different observation time is used on the diurnal cycle of the BTD and IDDI. Figure 4 shows the surface brightness temperature and IDDI diurnal cycle.

Finally the dust occurrence area image (IDDI Grid image or IDDI image overlaying false RGB image) and corresponding IDDI values (Fig. 3h) were produced to indicate the dust loading - SDS-IDDI by combining the BTD, IDDI, RAT and the spectral classification parameters. This product is generated every hour in daytime at 01:00-09:00 UTC. A whole dust event animation detected by FY-2C is eventually obtained daily in spring.

\section{Validation and results analysis}

\subsection{Validation with ground-based observation}

There are many kinds of surface observations for weather and special observation for SDS. Murayama et al. (2001) introduced a ground-based network including the lidar, sky radiometer, and optical particle counter that has been in use since 1997 to monitor the Asian dusts during springtime. Huge Asian dust events that occurred in the middle of April 1998 were captured by this network. CMA began to establish an operational observation network for SDS in north China since 2002 (Wang et al., 2007). These observations provide a full range of ground-based validation and relationship analysis data sources for remote sensing from space.

\subsubsection{Validation using synoptic SDS and $\mathrm{PM}_{10}$ data}

The ground-based synoptic observations for SDS monitoring are made at the CMA weather stations national wide. The visual visibility at each site is reported every three hours and four levels of SDS, i.e. floating dust, blowing dust, sand/dust storm (SDS), and severe SDS, are classified (Yang et al., 2007), which correspond to a visibility of $>10 \mathrm{~km}, 1 \mathrm{~km}-$ $10 \mathrm{~km}, 500 \mathrm{~m}-1 \mathrm{~km}$ and $<500 \mathrm{~m}$, respectively. Figure $5 \mathrm{a}$ shows the FY-2C dust detection results compared with the dusty records from weather ground stations (Fig. 5b). They are every consistent in dust event distribution except for areas with cloud covers. A good agreement was obtained between 

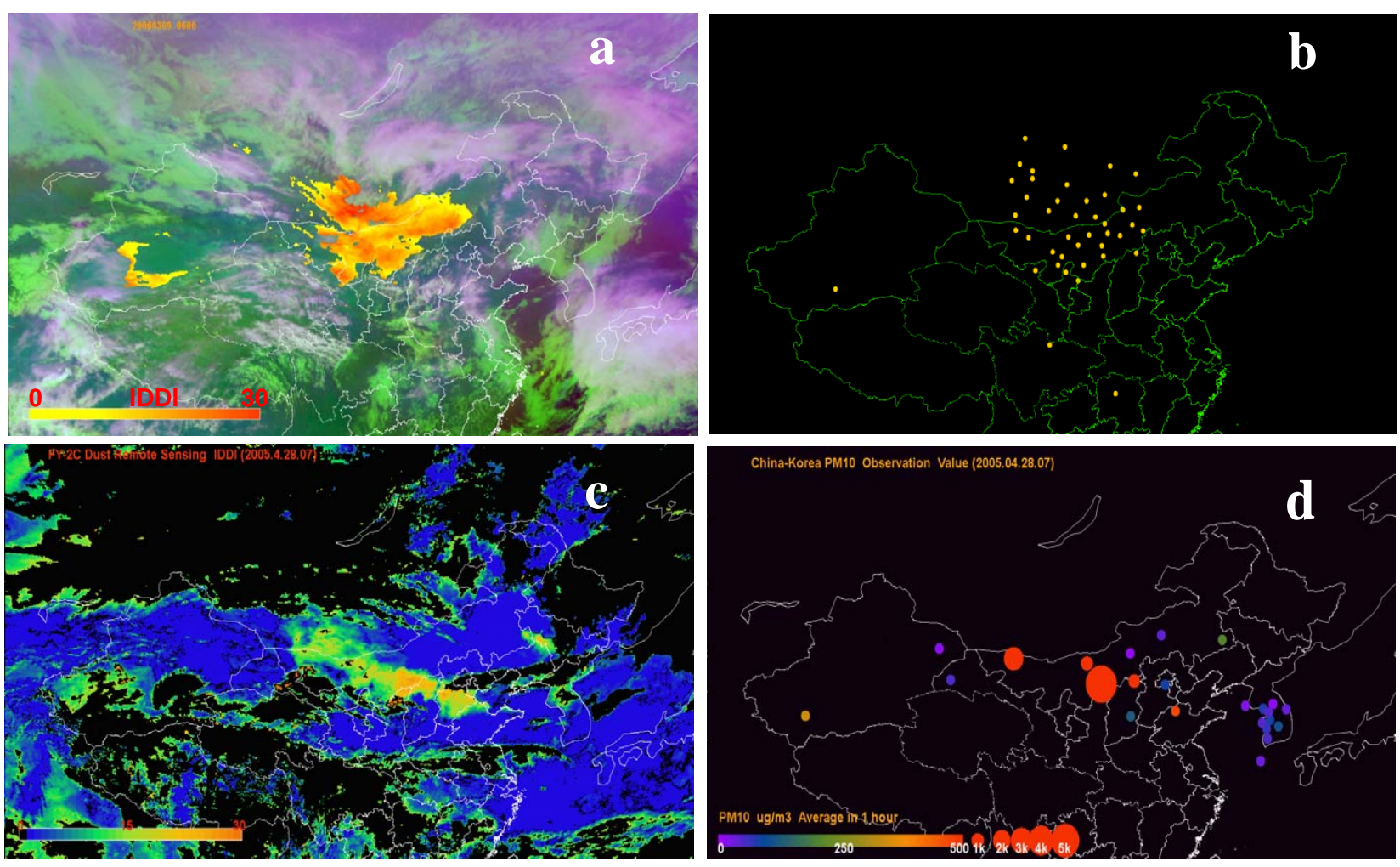

Fig. 5. Validation of FY-2C detection results with ground-based observation. (a) Dust detection results by FY-2C at 06:00 UTC on 9 March 2006. The yellow to red areas overlaying the false FY-2C GRB image are the dust target. The color scale of the areas means IDDI value. (b) shown the dusty stations (yellow points) from GTS weather observation record including Dust in suspend, Blowing Dust and dust storm at the same time as (a) image. (c) shown IDDI image from FY-2C at 04:00 UTC on 28 April 2005. (d) ground-observed PM 10 value in China and Korea at the same as (c) image.

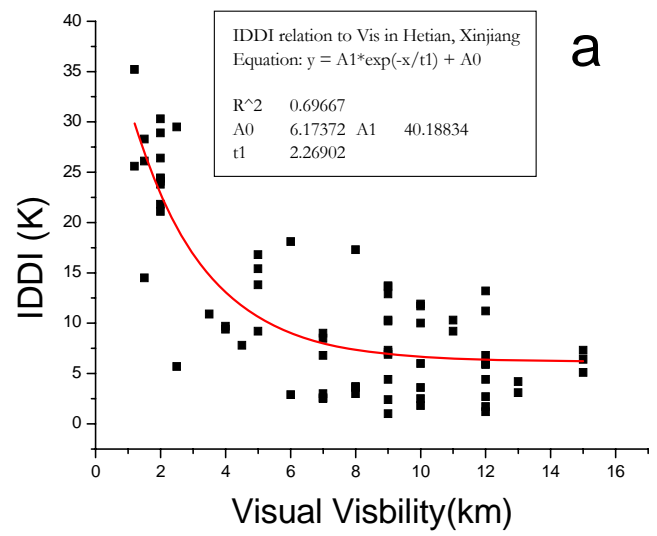

Fig. 6. SDS-IDDI relate to visibility from synoptic visibility data.

them and a quantitative relation between SDS-IDDI and visibility was established at various stations by the following nonlinear equation:

$\mathrm{SDS}-\mathrm{IDDI}=A 1^{*} \exp (-\mathrm{VIS} / t 1)+A 0$

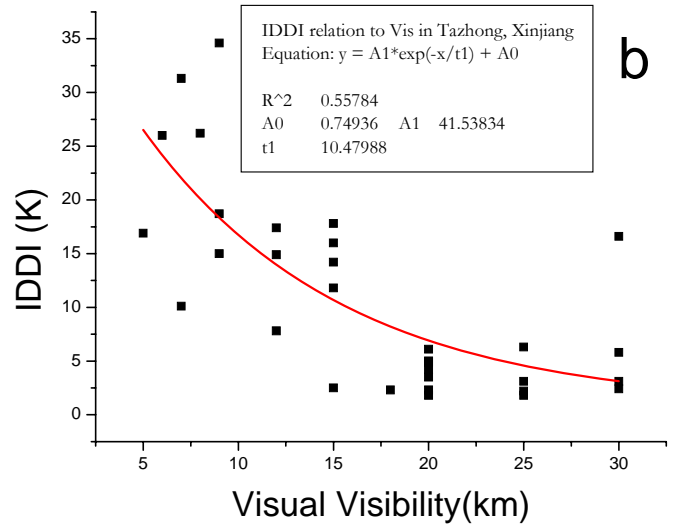

Examples of such relationship at two locations of Hetian $\left[37.13^{\circ} \mathrm{N}, 79.93^{\circ} \mathrm{E}\right]$ and Tazhong $\left[39.00^{\circ} \mathrm{N}, 83.67^{\circ} \mathrm{E}\right]$ are shown in Fig. 6 with fitting constants of $A 1, t 1$ and $A 0$. Obviously, these constants are location dependent. Niu et al. (2007) has evaluated all the net work data in China with the SDS-IDDI and developed a nation wide data base for the 

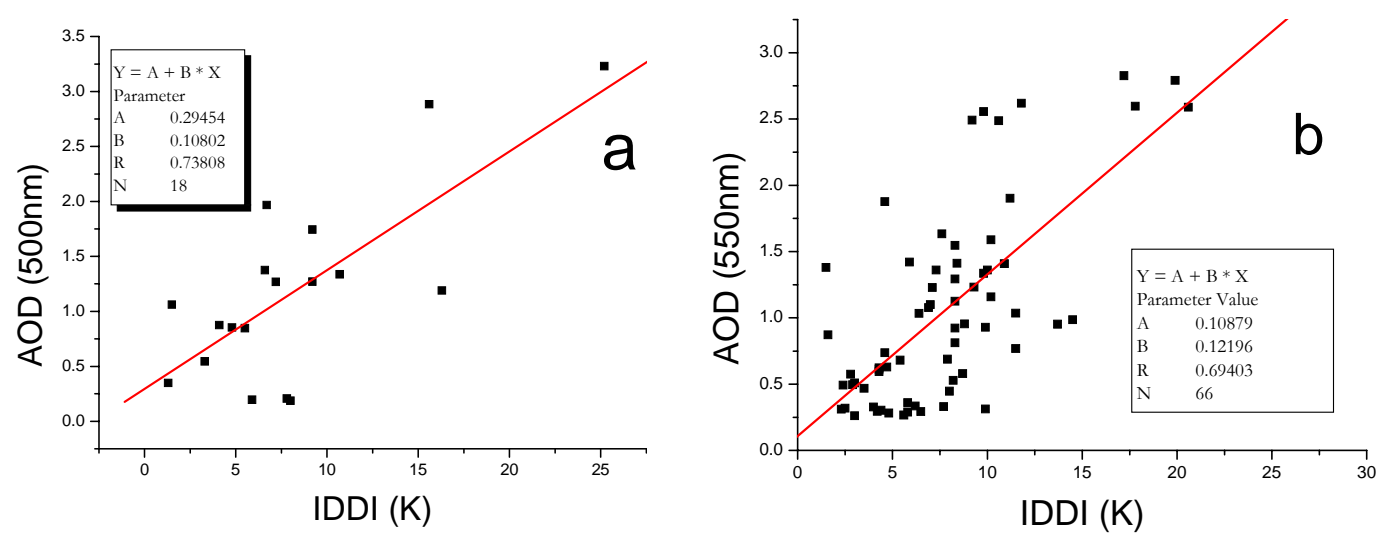

Fig. 7. SDS-IDDI Relate to aerosol optical depth from AERONET at (a) Dunhuang, 2001 and (b) from CE318 Sunphotometer Network in North China.
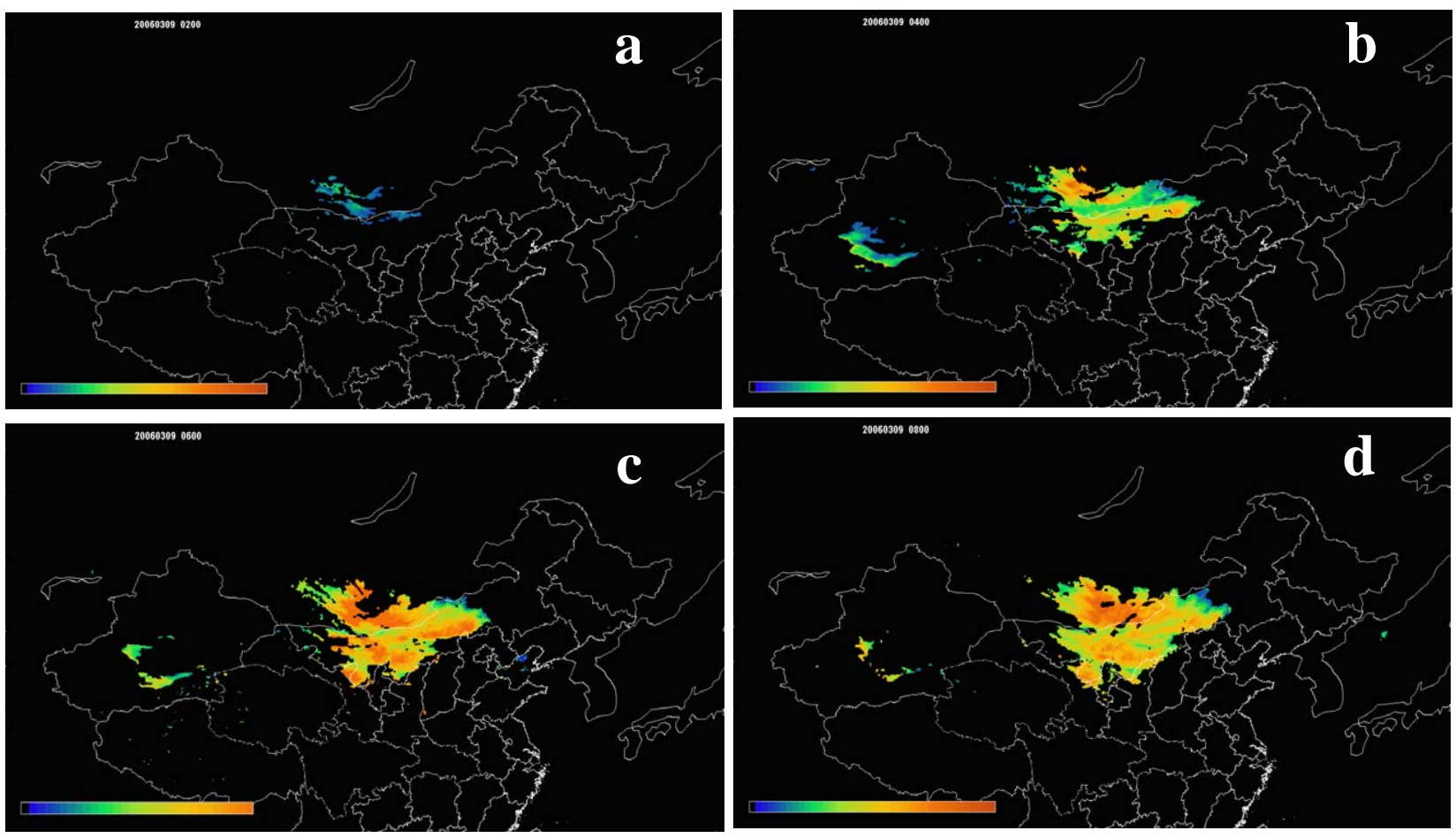

Fig. 8. Dust event motion animation detected by FY-2C on 9 March 2006, 02:00-08:00 UTC.

constants used in converting the visibility to SDS-IDDI in CUACE/Dust dust data assimilation scheme.

During the dust weather day, $\mathrm{PM}_{10}$ observation can validate the results from satellite observation exactly. From the $\mathrm{PM}_{10}$ value distribution at the same time, we can see the dust outbreak impacting area which is very consistent with FY2C IDDI spatial distribution. Figure 5c and d, respectively, shows the IDDI image and $\mathrm{PM}_{10}$ value of one dust case at 04:00 UTC in 28 April 2005.

\subsubsection{Validation using AOD}

Since the SDS_IDDI reflects the column loading of dust aerosols as the AOD by ground-based sunphotometer, a close relationship should exist. Figure 7 shows the relationship between AOD and SDS_IDDI at Dunhuang AERONET site and a site in north China. During the dusty weathers, the AOD and SDS-IDDI has the following relationship:

$$
\mathrm{AOD}=A+B^{*} \mathrm{IDDI}
$$




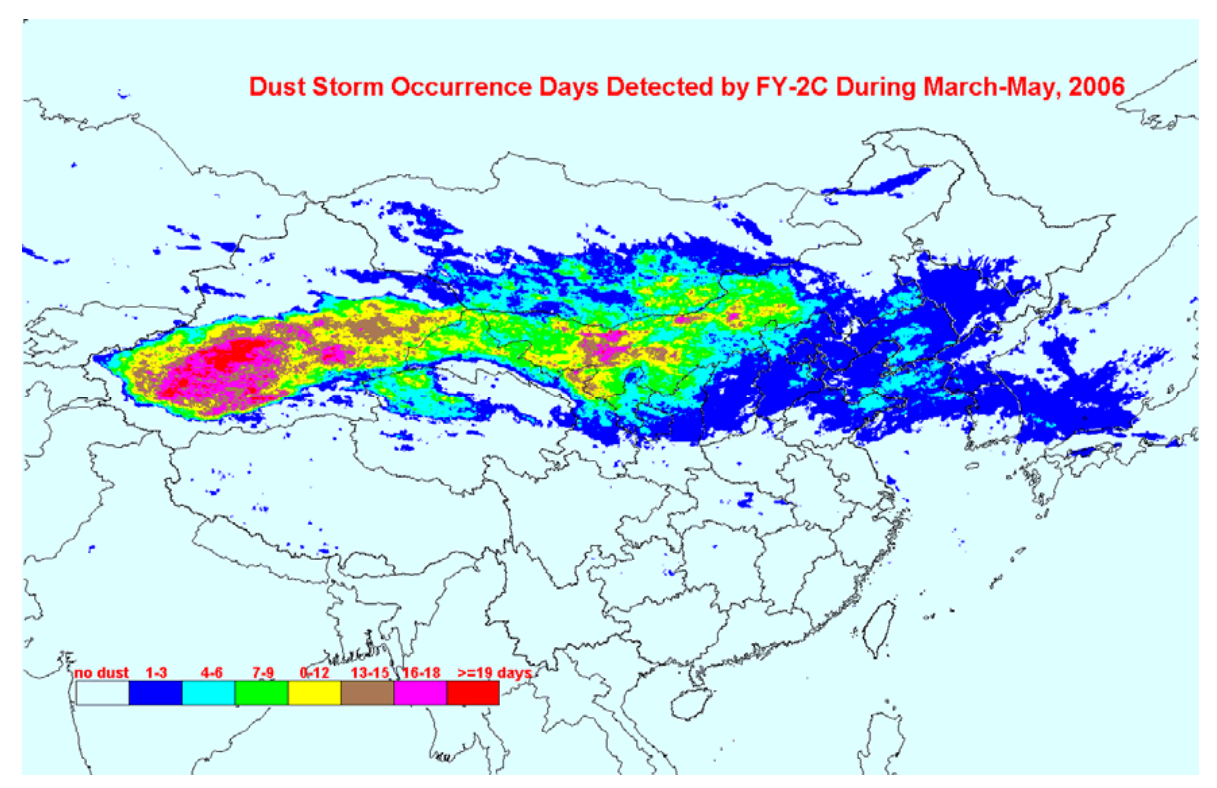

Fig. 9. Dust occurrence frequency accumulation statistic by FY-2C during March-May 2006.

where $A$ and $B$ are the fitting coefficients. When a heavy SDS occurs, there is no observation of sunphotometer or it is treated as cloud data.

\subsection{Applications of FY-2C SDS detection}

\subsubsection{The dust outbreak on 9 March 2006}

Northeast Asia, including North China, Mongolia, Korea and Japan, covering $70^{\circ} \mathrm{E}-140^{\circ} \mathrm{E}$ and $25^{\circ} \mathrm{N}-60^{\circ} \mathrm{N}$, is chosen as the domain for the operational dust product of FY-2C. A SDS distribution is generated from all results at one hour interval every day. Figure 8 shows the evolution of the first severe SDS process on 9 March in spring 2006 at 02:00, 04:00, 06:00 and 08:00 UTC. At the beginning phases, the dust outbreak formed at the border area between Mongolia and China at 02:00 UTC, and then it strengthened quickly in two hours and extended to the middle-west region. At the same time there was another relatively weak dust event came into being in the Taklamakan desert in Xinjiang province. The dust storm process had already attached into Gansu, Ningxia and Shanxi provinces in afternoon of 9 March. Surface observations confirmed the detection of this dust process by FY-2C (Wang et al., 2007; Yang et al., 2007).

\subsubsection{Long term detection analysis - spring 2006}

To evaluate a complete picture of the dust events in a dusty season, all the dust detection results in every hour can be accumulated to form monthly or seasonally mean SDS distributions for a dust occurrence frequency analysis. Over the arid and semi-arid regions of northern China and Mongolia, the dominant aerosol types are soil-dust particles originating in the desert and the Gobi in north China. Therefore the mean SDS-IDDI can be interpreted as dust emission and transport ranges. In order to use the SDS-IDDI as a means of measuring atmospheric dust loading, cloud must be identified and either masked or removed when conduct the mean processing monthly.

Figure 9 shows a spatial distribution of the totally dusty weather days during March-May, 2006. Three dust emission areas are visualized including Takilimakan, Badain Juran and Onqin Daga sand areas. This is consistent with the surface observations which identified three SDS occurrence centers, western China source, Mongolia source and northern China source (Wang et al., 2007).

\subsubsection{SDS data assimilation for CUACE/Dust in spring 2006}

The SDS-IDDI retrieved from the FY-2C has been used in a data assimilation system (DAS) (Niu et al., 2007) developed for the operational SDS forecasting system - CUACE/Dust. With other surface observation data, SDS-IDDI has substantially enhanced the prediction efficiency of CUACE/Dust. The seasonal mean TS score increased from 0.22 without DAS to 0.31 with DAS.

\section{Conclusion}

An operational dust detection algorithm that utilizes the multi-spectral channels of meteorological satellite geostationary imager from FY-2C was presented in this paper. The outputs of the dust detection provide a complete picture of the emission and transports of SDS outbreaks. The results 
indicate that the new DRAGI algorithm, which integrates several techniques including BTD, IDDI and RAT, is not only more sensitive to the presence of dust aerosols but also generally less prone to false alarms than the traditional split windows algorithm.

The retrieval results SDS-IDDI by this algorithm were compared with reasonable agreements to the synoptic data and other dust quantitative observations, including visibility, AOD and $\mathrm{PM}_{10}$. Relationships between SDS-IDDI and visibility and AOD were established to enable the conversion of SDS-IDDI to other SDS quantities. These relationships have been used in a SDS assimilation system to improve the forecasting accuracy of SDS in East Asia.

The new generation of instruments like SEVIRI onboard MSG offers an even better opportunity to detect dust clouds, especially at night, and future sensors such as the Advanced Baseline Imager (ABI) on the GOES-R platform (2013) and the Visible/Infrared Imager/Radiometer Suite (VIIRS) on the NPOESS platform (2008) will also offer additional operational capabilities. Future work will focus on utilizing these additional capabilities for automated dust detection during the day and night. The daytime detection philosophy can be applied to infrared channels to improve nighttime detection.

Acknowledgements. The authors wish to thank for the financial supports from the National Basic Research Program 973 of China (2006CB403701 and 2006CB403702) for this project. Thanks for the support from the National Natural Science Foundation of China (Project ID: 40606043). Special thanks to S. L. Gong of Environment Canada for his scientific advice and hard work to polish this manuscript.

Edited by: S. Gong

\section{References}

Ackerman, S. A.: Using the radiative temperature difference at 3.7 and $11 \mu \mathrm{m}$ to track dust outbreaks, Rem. Sens. Environ., 27, 129-133, 1989.

Ackerman, S. A.: Remote Sensing aerosols using satellite infrared observation, J. Geophys. Res., 102, 17 069-17 079, 1997.

Berk, A., Berstein, S., and Robertson, D. C.: MODTRAN: a medium resolution model LOWTRAN-7, Geophys. Lab., Hanscom AFB, MA, 1989.

Brooks, N.: Dust-climate interactions in the Sahel-Sahara zone of northern Africa, with particular reference to late twentieth century Sahelian drought, PhD Thesis Thesis, University of East Anglia, Norwich, UK, 2000.

Carlson, T. N.: Atmospheric turbidity in Saharan Dust Outbreaks as Determined by Analyses of Satellite Brightness Data, Mon. Weather Rev., 107, 322-335, 1978.

Cautenet, G., Legrand, M., Cautene, S., Bonnel, B., and Brognie, G.: Thermal Impact of Saharan Dust Land. Part I: Simulation, J. Appl. Meteorol., 31, 166-180, 1992.

Ellrod, G. P., Connell, B. H., and Hillger, D. W.: Improved detection of airborne volcanic ash using multispectral infrared satellite data, J. Geophys. Res., 108, AAC6.1-AAC6.13, 2003.
Simpson, J. J., Hufford, G., Pieri, D., and Berg, J.: Failures in detecting volcanic ash from a satellite-based technique, Rem. Sens. Environ., 72, 191-217, 2000.

Gong, S. L., Zhang, X. Y., Zhao, T. L., Zhang, X. B., Barrie, L. A., McKendry, I. G., and Zhao, C. S.: A Simulated Climatology of Asian Dust Aerosol and its Trans-Pacific Transport 2, Interannual Variability and Climate Connections, J. Climate, 19, 104-122, 2006.

Legrand, M., Cautenet, G., and Burie, J. C.: Thermal Impact of Saharan Dust over Land. Part 11: Application to Satellite IR Remote Sensing, J. Appl. Meteor., 181-193, 1992.

Legrand, M., Desbois, M., and Vovor, K.: Satellite Detection of Saharan DustOptimized Imaging during Nighttime, J. Climate, 1, 256-264, 1987.

Legrand, M., Bertrand, J. J., Desbois, M., Menenger, L., and Fouquart, Y.: The Potential of Infrared Satellite Data for the Retrieval of Sahara-Dust Optical Depth over Africa, J. Appl. Meteor., 28, 309-319, 1989.

Legrand, M., Plana-Fattori, A., and N'doumé, C.: Satellite detection of dust using the IR imagery of Meteosat: 1. Infrared difference dust index, J. Geophys. Res., 106, 18 251-18 274, 2001.

Middleton, N. J. and Goudie, A. S.: Saharan dust: Sources and trajectories, Transactions of the Institute of British Geographers NS, 26, 165-81, 2001.

Murayama, T., Sugimoto, N., and Uno, I.: Ground-based network observation of Asian dust events of April 1998 in east Asia, J. Geophys. Res., 106, 18317-18330, 2001.

Niu, T., Gong, S. L., Zhu, G. F., Liu, H. L., Hu, X. Q., Zhou, C. H., Wang, Y. Q., and Zhang, X. Y.: Data Assimilation of Dust Aerosol Observations for CUACE/Dust Forecasting System, Atmos. Chem. Phys. Discuss., 7, 8309-8332, 2007, http://www.atmos-chem-phys-discuss.net/7/8309/2007/.

Norton, C. C., Mosher, F. R., Hinton, B., Martin, D. W., Santek, D., and Kuhlow, W.: A Model for Calculating Desert Aerosol Turbidity over the Oceans from Geostationary Satellite Data, J. Appl. Meteor., 19, 633-644, 1980.

Pavolonis, M. J., Feltz, W. F., Heidinger, A. K., and Gallina, G. M.: A Daytime Complement to the Reverse Absorption Technique for Improved Automated Detection of Volcanic Ash, J. Atmos. Oceanic Technol., 23, 1422-1444, 2006.

Pergola, N., Tramutoli, V., Marchese, F., Scaffidi, I., and Lacava, T.: Improving volcanic ash cloud detection by a robust satellite technique, Rem. Sens. Environ., 90, 1-22, 2004.

Prata, A. J.: Observations of volcanic ash clouds in the 10-12micron window using AVHRR/2 Data, Int. J. Remote Sens., 10, 751-761, 1989a.

Prata, A. J.: Radiative transfer calculations for volcanic ash clouds, Geophys. Res. Lett., 16, 1293-1296, 1989b.

Shenek, W. E. and Curran, R. J.: The Detection of Dust Storms Over Land and Water With Satellite Visible and Infrared Measurements, Mon. Weather Rev., 102, 830-837, 1974.

Wald, A. E., Kaufman, Y. J., Tanre, D., and Gao, B. C.: Daytime and nighttime detection of mineral dust over desert using the thermal IR, J. Geophys. Res., 103, 32 307-32 313, 1998.

Wang, Y. Q., Zhang, X. Y., Gong, S. L., Zhou, C. H., Hu, X. Q., Liu, H. L., Niu, T., and Yang, Y. Q.: Surface observation of sand and dust storm in East Asia and its application in CUACE/Dust forecasting system, Atmos. Chem. Phys. Discuss., 7, 9115-9138, 2007 , 
http://www.atmos-chem-phys-discuss.net/7/9115/2007/.

Yang, Y. Q., Hou, Q., Zhou, C. H., Liu, H. L., Wang, Y. Q., and Niu, T.: Sand/dust storms over Northeast Asia and associated largescale circulations in spring 2006, Atmos. Chem. Phys. Discuss., 7, 9259-9281, 2007,

http://www.atmos-chem-phys-discuss.net/7/9259/2007/.
Zhang, P., Lu, N.-M., Hu, X.-Q., and Dong, C.-H.: Identification and physical retrieval of dust storm using three MODIS thermal IR channels, Global Planet. Change, 52, 197-206, 2006. 